\title{
2||-|||||||||||||||||||||||||||||||||||||||||||||||||||||||||||||||||.
}

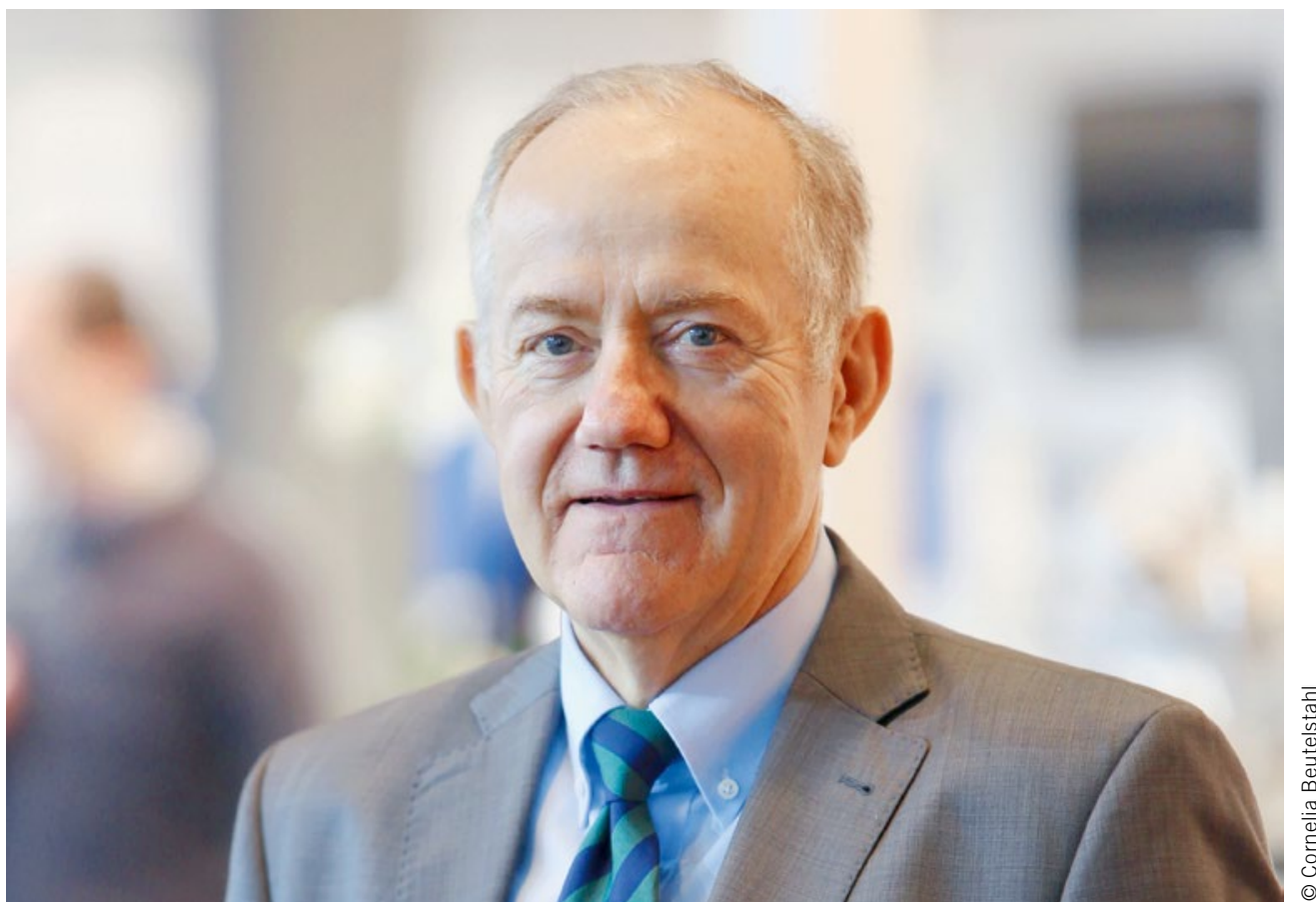

Wolfgang Maus

WM Engineering \& Consulting $\mathrm{GmbH}$

\section{Future Mobility: Physics Will Show the Way}

In the world of science, one thing is certain: our world and our lives are described by physics. This opinion is shared by scientists from other disciplines, such as engineering, biology (environment), chemistry (fuels) and even economics (prosperity).

However, physics and its sub-disciplines permit more or less optimised processes and even aberrations. It is a fact that we inevitably consume energy in order to live our lives. Albeit with poor efficiency. But as a result, we are able, for example in the case of mobility, to control large quantities of energy and to perform important work. Therefore, our prosperity today depends essentially on cheap fossil fuels and their economical use.

Mass motorisation and unsustainable urban emissions resulted in today's Euro 6 emissions standards. Thirty years ago, no-one would have considered them to be feasible. And further reductions are also being called for after the forthcoming introduction of RDE legislation. What would then be a sensible target?

The 2015 UN conference on climate change in Paris showed that $\mathrm{CO}_{2}$ emissions must be drastically reduced if the two-degree climate target is to be met. The transport sector is to expect a $60 \%$ reduction in $\mathrm{CO}_{2}$ by 2050 . And yet, by demanding an end to the use of fossil fuels, environmental politicians and NGOs are setting a nonsensical target. The intention is that no additional fossil-based $\mathrm{CO}_{2}$ should find its way into the earth's carbon cycle. But even the 2050 targets cannot be met with internal combustion engines and hybridisation. And what does the future hold?
EU legislators and NGOs do not believe that the mobility industry and energy providers have the competence to find a solution. In spite of an economically related increase in transport, Brussels focuses on intervention and restrictions.

The solutions it proposes are electric mobility and fuel cell drive systems. However, the carbon footprint must be evaluated from well to wheel and not from tank to wheel. These results would be a sobering wake-up call for politicians. The solution to the dual problem described above may be found in synthetic, carbon-neutral fuels and lubricants. $\mathrm{CO}_{2}$ recycling (CWtL) can be used to produce carbon-neutral fuels in the form of methane or methanol. OME as an alternative to fossil diesel fuel is already available today from China. Possible sources of $\mathrm{CO}_{2}$ are coal- and gas-fired power stations and cement factories. Blast furnace gas from steelworks, as a low-cost source of energy and $\mathrm{CO}_{2}$, could further reduce the already acceptable price of OME fuel. The FVV has shown that it may even be possible one day to capture $\mathrm{CO}_{2}$ from the air - but at a higher cost. Such monomolecular C1-OME fuels burn with low emissions in today's diesel engines. And by applying state-of-the-art exhaust aftertreatment technology, it should be possible, in the foreseeable future, to use "sub-zero-emission" vehicles to clean inner-city air. By contrast, electric mobility and the fuel cell will only offer zero emissions. It will be physics that will show the way towards the most sustainable solution. 